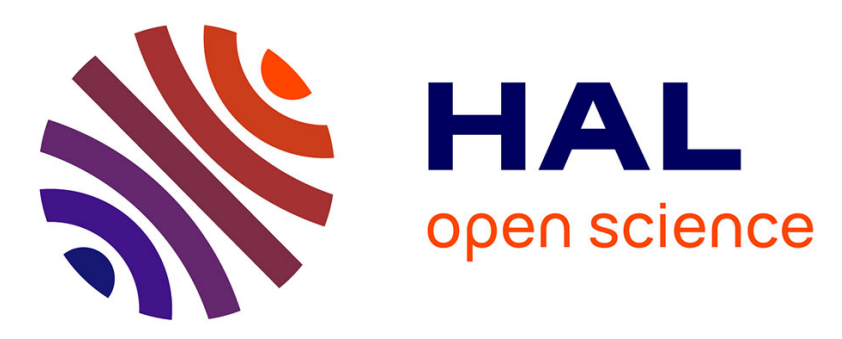

\title{
Passive rewilding may (also) restore phylogenetically rich and functionally resilient forest plant communities
}

Loïs Morel, Lou Barbe, Vincent Jung, Bernard Clément, Annik Schnitzler, Frederic Ysnel

\section{- To cite this version:}

Loïs Morel, Lou Barbe, Vincent Jung, Bernard Clément, Annik Schnitzler, et al.. Passive rewilding may (also) restore phylogenetically rich and functionally resilient forest plant communities. Ecological Applications, 2020, 30 (1), pp.e02007. 10.1002/eap.2007 . hal-02304431

HAL Id: hal-02304431

https://hal-univ-rennes1.archives-ouvertes.fr/hal-02304431

Submitted on 9 Dec 2019

HAL is a multi-disciplinary open access archive for the deposit and dissemination of scientific research documents, whether they are published or not. The documents may come from teaching and research institutions in France or abroad, or from public or private research centers.
L'archive ouverte pluridisciplinaire $\mathbf{H A L}$, est destinée au dépôt et à la diffusion de documents scientifiques de niveau recherche, publiés ou non, émanant des établissements d'enseignement et de recherche français ou étrangers, des laboratoires publics ou privés. 
DR. LOU BARBE (Orcid ID : 0000-0003-1800-407X)

Article type : Articles

Running head: Rewilding and native forest biodiversity

\section{Passive rewilding may (also) restore phylogenetically rich and functionally resilient forest plant communities}

Loïs More $^{1 *}$, Lou Barbe ${ }^{2}$, Vincent Jung ${ }^{2}$, Bernard Clément ${ }^{1}$, Annik Schnitzler ${ }^{3}$, and Frédéric Ysnel $^{1}$

${ }^{1}$ Géoarchitecture: Territoires, Urbanisation, Biodiversité, Environnement (G-TUBE EA 7462) Université de Rennes 1, Université de Brest, Campus de Beaulieu, 35042 Rennes, France, morellois@hotmail.com, bemiclement@gmail.com,frederic.ysnel@univ-rennes1.fr

${ }^{2}$ Écosystèmes, Biodiversité, Evolution (ECOBIO UMR 6553), CNRS, Université de Rennes 1, Campus de Beaulieu, 35042 Rennes, France, lou.barbe@univ-rennes1.fr, vincent.jung@univrennes1.fr

${ }^{3}$ Laboratoire Interdisciplinaire des Environnements Continentaux (LIEC UMR 7360), Université de Lorraine, CNRS, Campus Bridoux, rue du Général Delestraint, 57070 Metz, France, annick.schnitzler@univ-lorraine.fr

*Correspondence. E-mail: morellois@hotmail.com 


\section{Abstract}

Passive rewilding is increasingly seen as a promising tool to counterbalance biodiversity losses and recover native forest ecosystems. One key question, crucial to understanding assembly processes and conservation issues underlying land-use change, is the extent to which functional and phylogenetic diversity may recover in spontaneous recent woodlands. Here, we compared understorey plant communities of recent woodlands (which result from afforestation on agricultural lands during the $20^{\text {th }}$ century) with those of ancient forests (uninterrupted for several centuries) in a hotspot of farmland abandonment in western Europe. We combined taxonomic, functional, and phylogenetic diversity metrics to detect potential differences in community composition, structure (richness, divergence), conservation importance (functional originality and specialisation, evolutionary distinctiveness) and resilience (functional redundancy, response diversity). The recent and ancient forests harbored clearly distinct compositions, especially regarding the taxonomic and phylogenetic facets. Recent woodlands had higher taxonomic functional and phylogenetic richness and a higher evolutionary distinctiveness, whereas functional divergence and phylogenetic divergence were higher in ancient forests. On another hand, we did not find any significant differences in functional specialisation, originality, redundancy, or response diversity between recent and ancient forests. Our study constitutes one of the first empirical pieces of evidence that recent woodlands may spontaneously regain plant communities phylogenetically rich and functionally resilient, at least as much as those of ancient relict forests. As passive rewilding is the cheapest restoration method, we suggest that it should be a very useful tool to restore and conserve native forest biodiversity and functions, especially when forest areas are restricted and fragmented.

Key words: ancient forest; farmland abandonment; recent woodlands; response diversity; resilience; temporal forest continuity

\section{Introduction}

Rewilding is currently emerging as a novel conservation proposal to reduce anthropic forcing and restore the structural and functional complexity of degraded ecosystems (Fernádez et al., 2017; Torres et al., 2018). Considering the growing trend of farmland abandonment in developed countries (up to 16 million hectares by 2020 in Europe; Keenleyside et al., 2010), vast areas are being de-domesticated and offer a historical opportunity to rewild human-dominated landscapes. The debate on the interests of these emerging conservationist approaches is currently 
very lively, underscoring the need for further studies to rule on the ecological consequences, beneficial or not, of rewilding (Nogués-Bravo et al., 2016; Perino et al., 2019; Derham, 2019; Hayward et al., 2019; Pettorelli et al., 2019). In this perspective, passive rewilding - the spontaneous restoration of woodlands - is increasingly seen as a promising tool to restore nativeforest biodiversity and ecosystem services (Proença et al., 2012; Pereira and Navarro, 2015). A crucial socio-ecological issue is to determine the extent to which passive rewilding may allow for the restoration of rich forest biodiversity and ecosystem functions, at least like those of ancient relict forests that have become very rare (Cramer et al., 2008; Queiroz et al., 2014; Pereira and Navarro, 2015).

These last decades, considerable efforts have been made to pinpoint the ecological differences between plant communities of spontaneous recent woodlands (i.e. post-agricultural woodlands emerging spontaneously through a secondary succession process during the $20^{\text {th }}$ century) and those of ancient forests (i.e. forests uninterrupted for at least the last 150-400 years, sensu Hermy et al., 1999). Most of these investigations provided evidence that temporal forest continuity (i.e. the duration of an uninterrupted forest state) strongly influenced the taxonomic composition of forest plant communities, as well as the composition of life-history traits (Hofmeister et al., 2019). The interruption of temporal continuity indeed limits the recruitment and the dispersal of forest species, so that recent woodlands are often quite different from ancient forests (see Hermy and Verheyen, 2007 for a review). In particular, recent woodlands are distinguished from ancient forests by the lack, or the low frequency, of typical specialist forest species, mainly characterized by low dispersal capacities (large seeds, low fecundity, unassisted dispersal, Verheyen et al., 2003; Kimberley et al., 2013). As a consequence, recent woodlands resulting from farmland abandonment are often perceived negatively, especially in Europe since they are established on agroecosystems that benefit from a great socio-cultural value (Schnitzler, 2014; Queiroz et al., 2014).

The key question of the way functional diversity responds to passive rewilding still remains unanswered. Functional diversity is one of the most crucial informations to be explored so as to determine whether and how communities functionally support distinct and more or less diverse species that in turn provide different ecosystem properties and services (Cadotte et al., 2011; Mouillot et al., 2013). Functional diversity also sheds light on assembly processes, reflected by the structure of the niches occupied by communities such as their size, complementarity, and their 
degree of functional specialisation or originality (Pavoine and Bonsall, 2011; Mouillot et al., 2013). In particular, functional redundancy and response diversity are very relevant metrics for studying the ecological resilience of ecosystems (Mori et al., 2013), that is the ability of an ecosystem to absorb changes caused by disturbances (see Angeler and Allen, 2016). Functional redundancy, which refers to the number of species contributing to an ecosystem function, provides a powerful estimation of the community functional stability by indicating the extent to which ecological functions are ensured by multiple species. Response diversity gives insights into the resilience of communities by measuring how functionally similar species respond differently to disturbances (Elmqvist et al., 2003). Yet, we still ignore whether plant communities of recent woodlands differ functionally from ancient forests, and what the consequences on ecosystem properties and biodiversity conservation could be.

Phylogenetic diversity metrics can provide complementary, useful information to highlight the intrinsic conservation value of sites by focusing on the proportion of evolutionary history conserved within ecological communities (Winter et al., 2013; Frishkoff et al. 2014; Morelli et al., 2016; Harrison et al., 2018). The study of phylogenetic diversity in recent woodlands is also just beginning and has mainly focused on tropical fauna (e.g. Edwards et al., 2017). Phylogenetic diversity can also be used to understand assembly processes and species coexistence (Prinzing et al., 2016). Moreover, phylogenetic diversity may reflect functional diversity and hence impact ecosystem functions (Crisp and Cook, 2012), so that it can be used as a useful proxy for functional diversity, in particular when traits of interest are very numerous and tedious to measure. Phylogenetic richness basically represents the number of different lineages harbored in a community (Faith, 1992). Evolutionary distinctiveness and phylogenetic divergence illustrate the difference in the evolutionary history of species relatively to other species, and informs on the phylogenetic rarity of species and on diversification processes (Webb, 2002; Isaac et al., 2007). Yet, the way passive rewilding impacts the evolutionary history and conservation importance of forest plant communities remains largely unknown.

We used field data collected in one of the main hotspots of farmland abandonment in the EU (see Renwick et al., 2013), namely the Armorican massif (western France), to assess how temporal forest continuity reshapes the taxonomic, functional, and phylogenetic diversity of herbaceous forest plant communities. We investigated the extent to which composition and structure (so called $\beta$ - and $\alpha$-diversity) of plant communities may recover in recent woodlands as compared to ancient forests. We tested the differences in community composition, structure, conservation importance, 
and resilience capabilities, using several indices assessing (i) taxonomic, functional, and phylogenetic community composition, (ii) the main components of functional and phylogenetic diversity (richness, divergence), (iii) functional and phylogenetic distinctiveness, and (iv) functional redundancy and response diversity.

\section{Materials and Methods}

\section{Study sites, habitat conditions and floristic surveys}

The study was conducted in different forest environments in western France, in the Armorican massif (Appendix S1: Fig. S1). We selected 36 plots of $\sim 1$ ha of mesophilic, oakbeech dominated, mature forest within the regional biogeographical province (Appendix S1: Table S1), and thereby strongly limited the influence of environmental heterogeneity and stand maturity. We set apart ancient forests from recent woodlands by checking the temporal forest continuity of each forest site by consulting the historical Cassini map layers (year 1790) and the Napoleonic cadastre (year 1847). We defined ancient forests as uninterrupted forests (not to be mistaken with unlogged forests) for at least 230 years, and recent woodlands as forests resulting from afforestation during the $20^{\text {th }}$ century, i.e. no more than 120 years old. Our dataset included 24 plots in ancient forests (from 6 different forest sites) and 12 plots in recent woodlands (from two different forest sites). The site areas ranged from 200 ha to 4,000 ha.

Several habitat descriptors as well as Ellenberg Indicator Values (EIV) were used to characterize the habitat structure and the ecological conditions of the selected plots and ensure the environmental homogeneity of the dataset (Appendix S1: Table S2).

The vegetation composition of the understorey (below 2 meters and including woody species) was assessed in June-July 2014 and 2015 in each selected plot. The percent cover of each vascular plant species (101 in total) was recorded within $50-\mathrm{m}^{2}(10 \times 5 \mathrm{~m})$ plots. Plots were at least 100 meters away from the nearest forest edge to minimize edge effects.

\section{Selection of functional traits and phylogenetic analyses}

We selected a set of nine functional traits from the LEDA database (Kleyer et al., 2008; Appendix S1: Table S3) to obtain a multidimensional representation of plant functional variability related to resource acquisition, competitive capacities, dispersal abilities, and regenerative strategies. Consequently, these traits are simultaneously response and effect traits (Appendix S1: Table S3). We specifically selected (i) two vegetative traits linked to the leaf economic spectrum and associated to competitive abilities, resource use and allocation strategy (SLA, LDMC), (ii) 
four regeneration and dispersal traits (Dispersal syndrome, Pollination, Seed mass, and Start of flowering), and (iii) three integrative traits of the plant status considering global life-history strategies (Height, Life span, and Life form). For continuous data, all the available trait values were averaged per species. Missing trait values (2.1\% of the data) were estimated using Multivariate Imputation by Chained Equation (MICE), a procedure that efficiently predicts mean matching from observed life-history trait values (Penone et al., 2014). Prior to analyses, continuous traits were log-transformed to make their distribution more symmetric and to reduce the variance between traits. We tested the correlations between traits to reduce redundant information, but they were lower than 0.6 (Appendix S1: Fig. S2), so we kept the nine traits to perform analyses.

To assess phylogenetic diversity, we used the global supertree of Zanne et al. (2014). Among the 101 species we collected, 99 species (98\%) were included in the tree. We added the missing two species in the global tree by creating polytomies at the genus level.

\section{Taxonomic diversity}

We used species richness as an indicator of taxonomic $\alpha$-diversity (Magurran, 2004). For further comparisons at the $\alpha$-level between diversity metrics of recent woodlands and ancient forests, we used linear mixed-effect models (LMMs) to account for potential spatial autocorrelation between plots and for the hierarchical structure of our sampling design. In addition, this procedure also allows accounting the potential influence of initial abiotic conditions (for which geological substrates is a good proxy) of the selected plots that could interfere with the studied factor (forest category). Therefore, we used the forest category (ancient or recent) as a fixed effect and defined the hierarchical structure (sampling plots nested within study sites) as well as geologic substrates (Appendix S1: Table S1) as random effects. Species richness was logtransformed to improve model fitness after a first test with generalized linear mixed effects models (GLMMs).

We quantified variation in community species composition (so called taxonomic $\beta$-diversity) by measuring the dissimilarities between each pair of plots with Jaccard's index, an usual betadiversity metric weakly influenced by sampling error and thus adapted to restricted dataset such ours (Schroeder and Jenkins, 2018). We performed a non-metric multidimensional scaling (NMDS) to visualize the overall taxonomic $\beta$-diversity. Then, to evaluate whether assemblages of recent woodlands differed from ancient forests, we applied permutational multivariate analysis of 
variance (PERMANOVA) on the Jaccard dissimilarity matrix. We performed 10,000

permutations, restricted between sites and geological substrates to account for potential spatial autocorrelation between plots and for the hierarchical structure of the dataset (sampling plots nested within sites) as well as initial abiotic conditions. Finally, we assessed whether recent woodlands were more homogeneous between them than ancient forests. For this, we compared levels of within taxonomic $\beta$-diversity between the two forest categories by calculating $\beta$ dispersion, which measures the distance of communities from the centroid of a group in a multivariate space. The significance of the difference in the median distance was evaluated using permutation tests (999 permutations; Anderson et al., 2006).

\section{Functional diversity}

We quantified functional $\alpha$-diversity using several indices. First, we used multivariate indices: functional richness (FRic) and functional divergence (FDiv), that measure functional dissimilarities of communities within a multidimensional space (Villéger et al., 2008; see Table 1 for details about metrics and their meanings). Several traits were categorical, so we performed a principal coordinates analysis (PCoA) based on a Gower dissimilarity matrix computed on species traits. To find the best multidimensional space possible, we used the mean squared deviation (mSD) criterion, which measured how the initial functional distances (based on trait values) were accurately represented in the final multidimensional PCoA-based space, as recommended by Maire et al. (2015): the lower the mean squared deviation, the higher the quality of the functional space. We kept three dimensions for the functional space $(\mathrm{mSD}=0.008)$. All the functional metrics presented below were then calculated within this functional space. Second, we assessed the conservation importance of plant communities by selecting metrics that focused on the degree of specialisation and distinctiveness of functional traits regarding the overall species pool (i.e. the 101 species of our dataset): functional specialisation (FSpe) and functional originality (FOri; see Table 1). Third, we assessed the community stability and resilience of plant communities by calculating the functional redundancy (FR) and the response diversity (RD) of each assemblage (see Table 1 for details).

We estimated FR following de Bello et al. (2007) and Ricotta et al. (2016) which proposed a method allowing to account for continuous life-history traits and integrate species abundance and evenness in the calculation. In this framework, FR is defined as the extent to which a community is 'saturated' with species harboring similar traits rather simply the number of species noted within 
discrete functional groups (Ricotta et al., 2016). Here so, FR is measured as the difference between taxonomic diversity (with Simpson's index) and functional diversity (with Rao's quadratic entropy); redundancy is at a maximum when functional diversity is weak because all the species are functionally identical and as a minimum if functional diversity equals taxonomic diversity because all the species are functionally different.

To estimate RD, we followed Laliberté et al. (2010) who suggests assessing the variation in responses of functionally similar species to environmental changes (that is response diversity; Elmqvist et al., 2003) by calculating the mean functional dispersion (FDis) within the functional groups of each community. Since this method uses an index independent from species richness (FDis), it allows an assessment of response diversity that is not trivially related to functional redundancy (Laliberté et al. 2010; Mori et al., 2013). So, we first divided the species pool into functional groups to then assess the extent to which the responses of species contributing to similar functions (so within a single functional group) are diversified. This allows to assess whether the species and the functions they provide are potentially resilient to disturbances. Since it is irrational to represent functional relatedness between species using a dendrogram (i.e. assuming hierarchical differences), we used the $k$-means methods to partition functional groups within the previously built functional space. Note that we did not built two separate functional spaces (one for response groups and another for effect groups) such as Laliberté et al. (2010) because all traits we selected represent key characteristics of plant responses to environmental filtering as well as plant effects on ecosystem processes and services (see Appendix S1: Table S3). Thus, from the same functional space, we identified functional groups of species performing similar functions and then we measured the variation in responses of these species to environmental changes. The appropriate number of clusters (i.e. the functional groups) was determined using the Gap statistic (Tibshirani et al., 2001). This process, which avoids a subjective delimitation of groups, yielded nine functional group (Appendix S1: Figs S3-S4). Then, we calculated the mean functional dispersion (FDis) within the nine functional groups and within each community to assess response diversity of the sampled assemblages (Laliberté et al., 2010). For example, a community recording a high response diversity indicates that the species noted within the different functional groups present, will have various responses to ecological disturbances, which is a key parameter for the ecosystem resilience. The comparisons of functional $\alpha$-diversities between recent woodlands and ancient forests followed the same methods as the comparisons of taxonomic $\alpha$-diversity (i.e. LMMs, see above). 
We quantified functional $\beta$-diversity between communities from the two forest categories using the same methods as taxonomic $\beta$-diversity (NMDS, PERMANOVA and $\beta$-dispersion, see above). However, analyses ran on a dissimilarity matrix based on a Jaccard's derived index focusing on functional traits of species (Villéger et al., 2013).

\section{Phylogenetic diversity}

We quantified phylogenetic $\alpha$-diversity using indices recommended by Tucker et al. (2016): phylogenetic diversity (PD) for richness and mean pairwise distance (MPD) for divergence (see Table 1 for metrics details). We also evaluated the conservation importance by measuring the evolutionary distinctiveness of each community, i.e. the amount of unique evolutionary history supported by the assemblage (see Table 1 for details). Comparisons of phylogenetic $\alpha$-diversities between recent woodlands and ancient forests followed the same methods as comparisons of taxonomic and functional $\alpha$-diversities (i.e. LMMs, see above).

We quantified phylogenetic $\beta$-diversity between communities from the two forest categories using the same methods as for quantifying taxonomic and functional $\beta$-diversity (NMDS, PERMANOVA and $\beta$-dispersion, see above). However, analyses ran on a dissimilarity matrix based on a Jaccard's derived index focusing on the position of species along the phylogenetic tree (Leprieur et al., 2012).

\section{Comparison between $\alpha$-diversity indices and null models}

We compared functional and phylogenetic indices calculated for $\alpha$-diversity to null models to test whether functional and phylogenetic structures differed from random expectations. Used together, the richness and divergence indices provide good power to discriminate assembly processes (Mason et al., 2013). Specifically, random communities ( $\mathrm{n}=999)$ were generated by shuffling species labels across the functional matrix or the phylogenetic dendrogram pool. This approach maintained the species richness of each community but made the identities of those species random as regards the whole pool. The standardized effect sizes (SES) were used to measure the difference between observed values and null expectations: $\mathrm{SES}=\left(\mathrm{FD}_{\text {obs }}-\right.$ mean $\left.\left.\left(\mathrm{FD}_{\text {null }}\right)\right) / \mathrm{SD}_{\text {null }}\right)$. Positive SES values indicated functional or phylogenetic overdispersion, whereas negative values indicated clustering. Null values (i.e. showing no difference with null distribution) indicated random patterns of assembly. We used Wilcoxon's signed-rank test to test the statistical significance of average functional and phylogenetic $\alpha$-diversity as compared to the null model. 
All analyses were performed using R version 3.3.3 (R Core Team 2016). Prior treatments of the species-by-trait matrix and the phylogenetic dendrogram were computed using the packages 'labsdv', 'mice', 'picante' and the 'quality_funct_space' function (Maire et al., 2015); indices were calculated with the packages 'adiv', 'betapart', 'vegan' and the 'multidimFD' function (Maire et al., 2015); statistical tests were assessed using the 'Lme4' and 'permute' packages.

\section{Results}

\section{Environmental conditions of selected plots}

The variables describing habitat structure (canopy cover, basal area and diameter at breast height of the five largest trees (Oaks)) highlighted no difference between recent and ancient forests. Similarly, EIV indicated no significant difference in moisture degrees and light availability between the two forest categories. On the other hand, EIV showed that soils under recent woodlands had significantly higher $\mathrm{pH}$ values and nutrient concentrations than those under ancient forests (Appendix S1: Table S2).

\section{Taxonomic diversity}

A total of 101 plants species were collected across the 36 sampling plots. Among them, 38 species were found in the two forests categories, 31 were only found in recent woodlands (Appendix S1: Fig. S5) and 32 only in ancient forests. On average, species richness of communities was dramatically higher in recent woodlands than in ancient forests $(24.1 \pm 8 v$ s. 15.6 \pm 6.6 [mean $\pm \mathrm{sd}] ; p<0.05$, Wald's test; Fig. 1a).

NMDS showed strong separation of species composition between the plant communities of recent and ancient forests (Fig. 3). The PERMANOVA additionally showed significant differences in the taxonomic composition of plant communities between the two forest categories $(p=0.001)$. $\beta$-dispersion - a measure of within $\beta$-diversity - did not differ between recent woodlands and ancient forests (permutation-based test; $p=0.083$ ). 


\section{Functional diversity}

Functional richness was higher in recent woodlands, whereas functional divergence displayed an opposite pattern (Wald's test, $p<0.05$; Fig. 1a). Functional specialisation and functional originality, selected to assess conservation importance through a functional lens, showed no significant difference between the two forest categories (Wald's test; $p>0.05$; Fig. 2a). Moreover, functional redundancy and response diversity did not differ between recent woodlands and ancient forests (Wald's test; $p>0.05$; Fig. 2b).

The standardized effect size of functional richness (SES.FRic) did not differ from the random expectations for recent woodlands, but was significantly lower than the null distribution for ancient forests (Fig. 1b). The standardized effect size of functional divergence (SES.FDiv) significantly differed from random expectations for both forest categories, which exhibited clustered patterns, with a larger departure from null distribution for recent woodlands (Wilcoxon's rank test; $p>0.05$; Fig. $1 b)$.

NMDS showed a slight separation of functional composition between the two forest categories: within the ordination space, the functional composition of recent woodlands appeared as a subpart of the functional composition of ancient forests (Fig. 3). PERMANOVA confirmed that these differences were significant $(p=0.003)$, as well as $\beta$-dispersion. Therefore, functional dissimilarities in recent woodlands were significantly lower than in ancient forests (permutationbased test; $p=0.017)$.

\section{Phylogenetic diversity}

Phylogenetic diversity and evolutionary distinctiveness were much higher in recent woodlands (Wald's test; $p<0.05$; Fig. 1a, Fig. 2). Only phylogenetic divergence (i.e. the mean pairwise distance) was slightly higher in ancient forests.

The standardized size effects for phylogenetic diversity (SES.PD) and for mean pairwise distances (SES.MPD) within plant communities were significantly different from random expectations for recent woodlands, but did not differ from random expectations for ancient forests (Fig. 1b).

The NMDS separated the two forest categories as clearly as taxonomic composition, and much more clearly than functional composition (Fig. 3). Additionally, the PERMANOVA showed significant differences in the phylogenetic composition of plant communities between the two 
forest categories $(p=0.001) . \beta$-dispersion did not differ between recent woodlands and ancient forests (permutation-based test; $p=0.021$ ).

\section{Discussion}

We showed that herbaceous plant communities of recent and ancient forests harbored clearly distinct taxonomic and phylogenetic compositions whereas functional composition differed little. In addition, recent woodlands harbored more species, with different identities and different evolutionary histories. However, recent woodlands and ancient forests had very similar functional specialisation and originality, as well as very similar resilience capabilities.

\section{Contrasting changes in taxonomic, functional, and phylogenetic compositions}

Our results demonstrate that functional composition differs far less than taxonomic and phylogenetic composition between recent woodlands and ancient forests. A first interpretation could be related to the fact that phylogenetic diversity seems to be more sensitive to environmental changes than functional diversity: driven by macroevolutionary processes that shaped lifeorganisms based on their overall features, phylogenetic diversity may give us a more accurate proxy of niche dimensions than functional diversity, which is highly dependent on the life-history traits considered (Crisp and Cook, 2012; Prinzing et al., 2016). The weak functional dissimilarities between recent and ancient forests also suggests strong functional redundancy within the pool of understorey forest plants. Species related to different clades may indeed share very similar functional features, such as Conopodium majus and Hyacinthoides non-scripta, two medium early-flowering geophytes belonging to the clades Apiales (dicots) and Asparagales (monocots), respectively (Appendix S1: Fig. S5). In fact, shifts in functional composition, which are mainly characterized by a lower dissimilarity among plots of recent woodlands, seem to result more from the fact that recent woodlands lack the functional features observed in ancient forests than from the emergence of functionally different novel assemblages. Consequently, this result is consistent with the taxonomic and phylogenetic facet that also suggests a significant niche shift between the two forest categories. 


\section{Divergence in the plant communities of recent and ancient forests: a niche shift induced by a}

break in the temporal forest continuity?

Our results confirmed that recent woodlands, especially in western Europe where forests are highly fragmented, may harbor plant species and a life-history trait composition strongly different from ancient forests (Hermy and Verheyen, 2007; Kimberley et al., 2013; Kirby and Watkins, 2015). More originally, our findings reinforce the emerging idea that a break in the temporal continuity may also impact the ecological niche and related evolutionary history of the overall understorey communities (Baeten et al., 2015). A first interpretation of this compositional dichotomy may be related to dispersal limitation. Several ancient forest species absent or less frequent in recent woodlands (e.g. Vaccinum myrtillus; Appendix S1: Fig. S5) are indeed slowgrowing, poorly reproductive, and weak dispersers (Verheyen et al. 2003; Verheyen and Hermy, 2004; Baeten et al., 2015). As a consequence, their colonization of regrowth forests can take several decades or centuries, so that recent woodlands may exhibit a "colonization credit" with respect to ancient forest species (Bergès et al., 2015; Naaf and Kolk, 2015). Second, compositional variations between the two forest types may also result from disturbances of the soil biota by agricultural legacy, e.g. past fertilizations which may have increased mineral and organic nutrient concentrations, as we noted (Appendix S1: Table S2; Koerner et al., 1997). These post-agricultural conditions may thus prevent typical forest species from establishing in recent woodlands because they tend not to tolerate nutrient-rich soils, their mutualists may be lacking, or they cannot always compete with other established plants (Hermy and Verheyen, 2007). Several species indeed, mainly oligotrophic and acidophilic ones, known to be specialists of ancient forests (see Hermy et al., 1999), were only recorded or more frequently found in ancient forests, e.g. Hypericum pulchrum, Millium effusum, Oxalis acetosella (Appendix S1: Fig. S5). In addition, agricultural legacy may also explain the higher species richness and the recruitment of novel species such as Geum urbanum or Crataegus monogyna in recent woodlands (Appendix S1: Fig. S5). Such patterns remain rare in the literature but have been highlighted in regions with acidic, nutrientpoor soils and species-poor communities (Hermy and Verheyen, 2007). In these environments, such as the Armorican massif, past soil fertilizations may have indeed reduced nutrient limitations and thus facilitated the colonization of recent woodlands by a wider range of species than in ancient forests (Koerner et al., 1997; Graae, 2000).

However, we can note that it is tricky to disentangle the respective influences of past landuse legacies from those of potential pre-existing abiotic conditions: past deforestations were 
mainly carried out on nutrient-rich soils, so that the remaining ancient forests are often established on nutrient-poorer soils (Bergès et al., 2015). This could explain - at least partly - why some ancient plant species were absent from recent woodlands as well as why some recent plant species were absent from ancient forests. Nevertheless, the differences between both forest categories were noted while the variations in geological substrates were incorporated into the analyses, thus suggesting that the pre-existing conditions influenced marginally the biodiversity changes.

\section{Higher functional diversity and evolutionary history in recent woodlands might be due to lower niche-based filtering}

Our results tend to support the hypothesis that past land uses, at least in regions with acidic and nutrient-poor soils, may lead an enlargement of the niche occupied by the understorey plant communities. Higher functional richness and phylogenetic $\alpha$-diversity indeed suggest that plant communities filled a greater niche volume in recent woodlands than in ancient forests (Fig. 1a). This pattern is consistent across the three facets of biodiversity studied: we noted that functional and phylogenetic diversity were closely correlated with species richness $\left(\mathrm{r}^{2}=0.75,0.96 ; \mathrm{p}<0.001\right.$; respectively). According to Cadotte and Tucker (2018), such strong congruences with species richness are quite unusual and seem to be a particularity of balanced phylogenetic trees (with few isolated clades with singular trait combinations; see Appendix S1: Fig. S5). Thus, as each clade being represented by several species, the environmental selection of many clades (such as in the recent woodlands) necessarily leads to an increase in both species and phylogenetic richness. However, even in such specific contexts, these gains in biological diversity are not simply related to the effect size: compared to ancient forests, recent woodlands shown higher values of functional richness even after controlling for the effect size with null models (Fig. 1b). Moreover, this assumption of a weaker niche-based filtering in the recent woodlands is also corroborated by the lack of clustered patterns for both metrics (Fig. 1b): that suggests that habitat filtering little affected the functional and phylogenetic richness of these plant communities. In addition, our results illustrate that ancient forests harbor plant communities functionally and phylogenetically more divergent than those of recent woodlands (Fig. 1a-b). Such patterns are generally interpreted as a sign of strong biotic filtering, although the causes underlying overdispersion are still debated (Cadotte and Tucker, 2017). Given that ancient forest plant communities have been assembled for much longer than those of recent woodlands, it is indeed highly probable that biotic interactions were much more structuring. Thus, our results on functional and phylogenetic $\alpha$-diversity 
converge on the interpretation that past land uses seem to lead to shifts in assembly processes which in turn contribute to accentuate the differences between recent and ancient forests.

\section{Beyond singularities: convergence of conservation importance and resilience capabilities}

\section{between recent and ancient forests}

Surprisingly, recent woodlands harbored understorey communities as functionally specialized, original, redundant, and potentially robust to disturbances as those of ancient forests. We expected recent woodlands to harbor degraded and more vulnerable communities, i.e. less specialized, distinct, and resilient species (Ghazoul et al., 2015; Kirby and Watkins, 2015), notably because of the lack of specialist ancient forest species. Several causes may explain these results. First, this relative rapid recovery (in about a century) of community structures may have been favored by an initially weakly fragmented landscape. Hedgerow networks were indeed still dense in the region in the early $20^{\text {th }}$ century, when the development of the studied recent woodlands began. These hedges may have conserved typical forest species such as Polygonatum multiflorum and made it easier for them to colonize recent woodlands (Appendix S1: Fig. S5; Gloaguen et al., 1994). Second, the functional convergence between ancient forests and recent woodlands might also be viewed as the effect of the degradation of ancient forests, rather than only as the ability of recent woodlands to rapidly recover highly resilient, original and specialized plant communities. Forest management of ancient forests may have indeed had a strong impact on biodiversity and functions, and potentially contributed to reduce functional differences between recent woodlands and ancient forests (Hermy and Verheyen, 2007; Kirby and Watkins, 2015). Third, another potential explanation could be that plant species characteristic of earlier successional stages remain in recent woodlands (plants of forested stages nevertheless, given the functional similarity between the two categories). These species may introduce functional features that compensate for the lack of those of the typical forest species; for example, Crateagus monogyna was much more present in recent woodlands and had a similar high degree of functional specialisation to Taxus baccata, another shrub-tree only found in ancient forests (Appendix S1: Fig. S5). However, species composition differences can persist over time (Baeten et al., 2010), so we assume that the functional convergence between recent and ancient forests is not a mere temporary oddity. Overall, the present study shows that recent woodlands can spontaneously recover the high functional resilience and conservation importance of ancient forests although they harbor plant communities with clearly distinct taxonomic and phylogenetic compositions. 


\section{Passive rewilding as a tool for conserving and restoring forest biodiversity}

Our results provide evidence that spontaneous recent woodlands may play a significant role in conserving original, resilient, and highly diverse forest plant communities. We confirmed that ancient forests are important for the conservation of assemblages inherited from the pre-industrial period (Hermy and Verheyen, 2007; Bergès et al., 2015; Kirby and Watkins, 2015), especially because of the specificity of their species and lineage composition. But we also showed that recent woodlands, by harboring a greater evolutionary history, may act as forest-biodiversity reservoirs and thus help to conserve the regional eco-evolutionary potential (Winter et al., 2013). Moreover, recent woodlands potentially cover a diversity and a complexity of ecosystem properties comparable to those of ancient forests, since the degrees of originality and specialisation are maintained. And this is true even if the nature of these properties may vary slightly due to slight changes in functional composition. More particularly, in the current climate change perspective, such capacities to respond to disturbances expected to intensify over time (e.g. hydric stress) appear crucial for the conservation of forest biodiversity and related ecological services. For these reasons, we argue that farmland abandonment can be very favorable for biodiversity, at least in some biogeographical and ecological contexts (see also the review by Queiroz et al., 2014). Obviously, all species will not benefit of passive rewilding; there will be both winners and losers (Carver 2019 in Pettorelli et al., 2019 ). Nevertheless, there is growing evidence that farmland abandonment is not systematically synonymous of ecological impoverishment, especially when biodiversity is studied through several distinct components and not only according to species richness and patrimonial value. So, recent researches shown that ecosystem de-domestication may benefit for several taxa, such as birds (Hanioka et al., 2018), ground-beetles (Yamanaka et al., 2017), moths (Mirauda et al., 2019) or spiders (Morel et al., 2019) and thus enrich ecological communities at both local and landscape scales.

Nevertheless, further research is still needed, notably to confirm our results in other contexts (e.g. after decades of intensive agricultural exploitation) and/or with a broader sampling, especially of recent woodlands. Indeed, as large and contiguous post-agricultural forests are rare in fragmented landscapes (especially in Brittany), it is difficult to balance sampling design enough to draw up an inventory representative of all situations. Our results, based on parametric statistical models and showing homogeneous variances for almost all the metrics assessed (see Appendix S1: Table S4), seem robust enough to consider that the recent woodlands studied here have significant 
resilience capacities. However, there is a non-zero probability that, in other contexts, recent woodlands do not spontaneously, and as quickly, recover biodiversity features similar to those of relictual ancient forests. Overall and despite these uncertainties, as passive rewilding is the cheapest restoration method, we suggest that it should be a very useful tool for nature conservation, either to restore regional forest plant biodiversity when forest areas are restricted and fragmented or, at least, to recover an original nature aesthetic, little influenced by human, and which has become very rare in western Europe.

\section{Acknowledgments}

This work was supported by the 'Région Bretagne', 'Conseil départemental des Côtes d'Armor', 'Conseil départemental d'Ille et Vilaine' and 'Communauté de communes de Plouha-Lanvollon'. We also would like to thank the military camp of St-Cyr-Coëtquidan for their help in data collection. We are also very grateful to Quentin Dilasser who helped in the proofreading of the manuscript. Finally, we thank the three anonymous reviewers for their careful reading of our manuscript and their insightful comments.

\section{Literature Cited}


Anderson, M.J., Ellingsen, K.E., McArdle, B.H., 2006. Multivariate dispersion as a measure of beta diversity. Ecology Letters, 9: 683-693.

Angeler, D.G., Allen, C.R. 2016. Quantifying resilience. Journal of Applied Ecology 53: 617-624. Baeten, L., Davies, T.J., Verheyen, K., Van Calster, H., Vellend, M. 2015. Disentangling dispersal from phylogeny in the colonization capacity of forest understorey plants. Journal of Ecology 103: $175-183$.

Baeten, L., Hermy, M., Van Daele, S., Verheyen, K. 2010. Unexpected understorey community development after 30 years in ancient and post-agricultural forests. Journal of Ecology 98: 14471453.

Bergès, L., Avon, C., Arnaudet, L., Archaux, F., Chauchard, S., Dupouey, J.-L. 2015. Past landscape explains forest periphery-to-core gradient of understorey plant communities in a reforestation context. Diversity and Distribution 22: 3-16.

Cadotte, M.W., Carscadden, K., Mirotchnick, N. 2011. Beyond species: functional diversity and the maintenance of ecological processes and services: Functional diversity in ecology and conservation. Journal of Applied Ecology 48: 1079-1087.

Cadotte, M.W., Tucker, C.M. 2017. Should Environmental Filtering be Abandoned? Trends in Ecology and Evolution 32: 429-437.

Cadotte, M.W., Tucker, C.M. 2018. Difficult decisions: Strategies for conservation prioritization when taxonomic, phylogenetic and functional diversity are not spatially congruent. Biological Conservation 225: 128-133.

Cramer, V.A., Hobbs, R.J., Standish, R.J. 2008. What's new about old fields? Land abandonment and ecosystem assembly. Trends in Ecology and Evolution 23: 104-112.

Crisp, M. D., Cook, L. G. 2012. Phylogenetic niche conservatism: what are the underlying evolutionary and ecological causes? New Phytologist 196: 681-694.

De Bello, F., Lepš, J., Lavorel, S., Moretti, M. 2007. Importance of species abundance for assessment of trait composition: an example based on pollinator communities. Community Ecology 8: 163-170.

Derham,T. T. 2019. In defence of 'rewilding'-a response to Hayward et al. (2019). Biological Conservation, in press. 
Edwards, D. P., Massam, M. R., Haugaasen, T., Gilroy, J. J. 2017. Tropical secondary forest regeneration conserves high levels of avian phylogenetic diversity. Biological Conservation 209: 432-439.

Elmqvist, T., Folke, C., Nyström, M., Peterson, G., Bengtsson, J., Walker, B., Norberg, J. 2003. Response diversity, ecosystem change, and resilience. Frontiers in Ecology and the Environment 1: 488-494.

Faith, D. P. 1992. Conservation evaluation and phylogenetic diversity. Biological Conservation 61: $1-10$.

Fernández, N, Navarro L.M., Pereira, H.M. 2017. Rewilding: a call for boosting ecological complexity in conservation. Conservation Letters 10: 276-278.

Frishkoff, L. O., Karp, D. S., M'Gonigle, L. K., Mendenhall, C. D., Zook, J., Kremen, C., Hadly, E. A., Daily, G.C. 2014. Loss of avian phylogenetic diversity in neotropical agricultural systems. Science 345: 1343-1346.

Ghazoul, J., Burivalova, Z., Garcia-Ulloa, J., King, L.A. 2015. Conceptualizing Forest Degradation. Trends in Ecology and Evolution 30: 622-632.

Gloaguen, J.C, Rozé, F., Clément, B., Touffet, J., Forgeard, F. 1994. Etude des successions après abandon des pratiques culturales en Bretagne. Acta Botanica Gallica 141: 691-706.

Graae, B. J. 2000. The effect of landscape fragmentation and forest continuity on forest floor species in two regions of Denmark. Journal of Vegetation Science 11: 881-892.

Hanioka, M., Yamaura, Y., Senzaki, M., Yamanaka, S., Kawamura, K., Nakamura, F. 2018. Assessing the landscape-dependent restoration potential of abandoned farmland using a hierarchical model of bird communities, Agriculture, Ecosystems \& Environment 265: 217-225.

Harrison, T., Gibbs, J., Winfree, R. 2018. Phylogenetic homogenization of bee communities across ecoregions. Global Ecology and Biogeography 27: 1457-1466.

Hayward, M.W. et al. 2019. Reintroducing rewilding to restoration - Rejecting the search for novelty. Biological Conservation 233: 255-259.

Hermy, M., Verheyen, K. 2007. Legacies of the past in the present-day forest biodiversity: a review of past land-use effects on forest plant species composition and diversity. Ecological Research 22: 361-371. 
Hermy, M., Honnay, O., Firbank, L., Grashof-Bokdam, C., Lawesson, J.E. 1999. An ecological comparison between ancient and other forest plant species of Europe, and the implications for forest conservation. Biological Conservation 91: 9-22.

Hofmeister, J. et al. 2019. Shared affinity of various forest-dwelling taxa point to the continuity of temperate forests. Ecological Indicators $101: 904-912$.

Isaac, N.J.B., Turvey, S.T., Collen, B., Waterman, C., Baillie, J.E.M. 2007. Mammals on the EDGE: Conservation Priorities Based on Threat and Phylogeny. PLOS ONE 2: e296.

Keenleyside, C., Tucker, G., McConville, A. 2010. Farmland abandonment in the eu: an assessment of trends and prospects. London: Institute for European Environmental Policy.

Kimberley, A., Blackburn, G.A., Whyatt, J.D., Kirby, K., Smart, S.M. 2013. Identifying the trait syndromes of conservation indicator species: how distinct are British ancient woodland indicator plants from other woodland species? Applied Vegetation Science 16: 667-675.

Kirby, K., Watkins, C. (eds) 2015. Europe's changing woods and forests: from Wildwood to managed landscapes. CAB Int, Wallingford.

Kleyer, M. et al. 2008. The LEDA Traitbase: a database of life-history traits of the Northwest European flora. Journal of Ecology 96: 1266-1274.

Koerner, W., Dupouey, J.L., Dambrine, E., Benoit, M. 1997. Influence of past land use on the vegetation and soils of present day forest in the vosges mountains, france. Journal of Ecology 85: $351-358$.

Laliberté, E., et al. 2010. Land-use intensification reduces functional redundancy and response diversity in plant communities. Ecology Letters 13: 76-86.

Leprieur, F., Albouy, C., De Bortoli, J., Cowman, PF., Bellwood, D.R., Mouillot, D. 2012. Quantifying phylogenetic beta diversity: distinguishing between "true" turnover of lineages and phylogenetic diversity Gradients. PLoS ONE 7: e42760.

Magurran, A. 2004. Measuring Biological Diversity. Blackwell Science, Oxford, UK.

Maire, E., Grenouillet, G., Brosse, S., Villéger, S. 2015. How many dimensions are needed to accurately assess functional diversity? A pragmatic approach for assessing the quality of 
functional spaces: Assessing functional space quality. Global Ecology and Biogeography 24: 728740 .

Mason, N.W.H., de Bello, F., Mouillot, D., Pavoine, S., Dray, S. 2013. A guide for using functional diversity indices to reveal changes in assembly processes along ecological gradients. Journal of Vegetation Science 24: 794-806.

Miranda, M.D., Pererira, H.M., Corley, M.F.V., Merckx, T. 2019. Beta diversity patterns reveal positive effects of farmland abandonment on moth communities. Scientific reports 9(1549).

Morel, L., Dujol, B., Courtial, C., Vasseur, M., Leroy, B., Ysnel, F. 2019. Spontaneous recovery of functional diversity and rarity of ground-living spiders shed light on the conservation importance of recent woodlands. Biodiversity and Conservation 28: 687-709.

Morelli, F., Benedetti, Y., Ibáñez-Álamo, J.D., Jokimaki, J., Mänd, R., Tryjanowski, P., Møller, A.P. 2016. Evidence of evolutionary homogenization of bird communities in urban environments across Europe. Global Ecology and Biogeography 25: 1284-1293.

Mori, A.S., Furukawa, T., Sasaki, T. 2013. Response diversity determines the resilience of ecosystems to environmental change. Biological Reviews 88: 349-364.

Mouillot, D., Graham, N.A.J., Villéger, S., Mason, N.W.H., Bellwood, D.R. 2013. A functional approach reveals community responses to disturbances. Trends in Ecology and Evolution 28: 167177.

Naaf, T., Kolk, J. 2015. Colonization credit of post-agricultural forest patches in NE Germany remains 130-230 years after reforestation. Biological Conservation 182:155-163.

Nogués-Bravo, D., Simberloff, D., Rahbek, C. \& Sanders, N.J. 2016. Rewilding is the new Pandora's box in conservation. Current Biology 26: R87-R91.

Pavoine, S., Bonsall, M.B. 2011. Measuring biodiversity to explain community assembly: a unified approach. Biological Reviews 86: 792-812.

Penone, C., et al. 2014. Imputation of missing data in life-history trait datasets: which approach performs the best? Methods in Ecology and Evolution 5: 961-970.

Pereira, H.M., Navarro, L.M. (eds). 2015. Rewilding European Landscapes. Springer, New- York. Perino, A. et al. 2019. Rewilding complex ecosystems. Science 36(6438). 
Pettorelli, N., Durant, S. D., du Toit, J. T. (eds). 2019. Rewilding. Cambridge University Press.

Prinzing, A. et al. 2016. Benefits from living together? Clades whose species use similar habitats may persist as a result of eco-evolutionary feedbacks. New Phytologist 213: 66-82.

Proença, V., Honrado, J., Pereira, H.M. 2012. From Abandoned Farmland to Self-Sustaining Forests: Challenges and Solutions. Ecosystems 15: 881-882.

Queiroz, C., Beilin, R., Folke, C., Folke, R. 2014. Farmland abandonment: threat or opportunity for biodiversity conservation? A global review. Frontiers in Ecology and the Environment 12: 288-296.

R Core Team., 2016 R: A Language and Environment for Statistical Computing. R Foundation for Statistical Computing. Vienna, Austria.

Renwick, A., Jansson, T., Verburg, P.H., Revoredo-Giha, C., Britz, W., Gocht, A., McCracken, D. 2013. Policy reform and agricultural land abandonment in the EU. Land Use Policy 30, 446-457.

Ricotta, C., Bello, F., Moretti, M., Caccianiga, M., Cerabolini, B. E. L., Pavoine, S. 2016.

Measuring the functional redundancy of biological communities: a quantitative guide. Methods in Ecology and Evolution 7: 1386-1395.

Schnitzler, A. 2014. Towards a new European wilderness: Embracing unmanaged forest growth and the decolonisation of nature. Landscape Urban Planning 126: 74-80.

Schroeder, P. J. and Jenkins, D. G. 2018. How robust are popular beta diversity indices to sampling error? Ecosphere 9(2): e02100.

Tibshirani, R., Walther, G., Hastie, T. 2001. Estimating the number of clusters in a data set via the gap statistic. Journal of the Royal Statistical Society: Series B (Statistical Methodology) 63, 411423.

Torres, A. et al. 2018. Measuring rewilding progress. Philosophical Transactions of the Royal Society B 373: 20170433.

Tucker, C.M. et al. 2016. A guide to phylogenetic metrics for conservation, community ecology and macroecology: A guide to phylogenetic metrics for ecology. Biological Reviews 92: 698-715. Verheyen, K., Hermy, M. 2004. Recruitment and growth of herb-layer species with different colonizing capacities in ancient and recent forests. Journal of Vegetation Science 15: 125-134. 
Verheyen, K., Honnay, O., Motzkin, G., Hermy, M., Foster, D.R. 2003. Response of forest plant species to land-use change: a life-history trait-based approach. Journal of Ecology 91: 563-577.

Villéger, S., Mason, N.W., Mouillot, D. 2008. New multidimensional functional diversity indices for a multifaceted framework in functional ecology. Ecology 89: 2290-2301.

Villéger S., Grenouillet G., Brosse S. 2013. Decomposing functional $\beta$-diversity reveals that low functional $\beta$-diversity is driven by low functional turnover in European fish assemblages:

Decomposing functional $\beta$-diversity. Global Ecology and Biogeography 22: 671-681.

Webb, C.O., Ackerly, D.D., McPeek, M.A. and Donoghue, M.J. 2002. Phylogenies and community ecology. Annual Review of Ecology, Evolution and Systematics 33: 475-505.

Winter, M., Devictor, V., Schweiger, O. 2013. Phylogenetic diversity and nature conservation: where are we? Trends in Ecology and Evolution 28: 199-204.

Yamanaka, S., Akasaka, T., Yabuhara, Y., Nakamura, F. 2017. Influence of farmland abandonment on the species composition of wetland ground beetles in Kushiro, Japan. Agriculture, Ecosystems and Environment 249: 31-37.

Zanne, A.E. et al. 2014. Three keys to the radiation of angiosperms into freezing environments. Nature 506: 89-92.

\section{Data Availability:}

Data are available on Figshare: https://doi.org/10.6084/m9.figshare.9764990.v1 


\section{Tables}

Table 1 Overview of the functional and phylogenetic diversity indices used in the study at the $\alpha$ level. We indicated whether the index was weighted by species abundance (assessed by percent cover) (column $\mathrm{Ab}$ ) and whether it was influenced by species richness (column Ri).

Table 1

\begin{tabular}{llll}
\hline Measure & Metric description & Ab & Ri References
\end{tabular}

\section{Richness}

Functional

richness (FRic)

The volume of functional space occupied by a community.

Faith's

Phylogenetic

Diversity (PD)
The sum of the total phylogenetic branch lengths occupied by the species of a community.

High richness indicates that species have contrasted trait values / phylogenetic positions; it suggests high levels of niche size and evolutionary history occupied by a community.

\section{Divergence}

\section{Functional}

divergence (FDiv)

Mean Pairwise

Distances (MPD)
The distribution of species abundance in a functional space occupied by a community.

The mean pairwise distances separating taxa in a community.

High divergence indicates that abundant species have the most extreme trait values / phylogenetic position within the community; it suggests high levels of niche differentiation.
Villéger et

al., 2008

Villéger et

al., 2008

Webb, 2002

\section{Conservation \\ importance}

Functional

specialisation
The mean distance between the species from a given community and the centroid of the overall functional space (i.e. with regard to
Yes No Mouillot et 
Functional

originality (FOri)

The mean distance between the species from a given community and their nearest neighbors within the overall functional space.

Evolutionary

distinctiveness

(ED)

The sum of values per branch length (from tip to root), divided by the number of species subtending each branch.

High values of FSpe, FOri and/or ED suggest a high conservation importance of the studied community (species traits and evolutionary histories are rare with regard to the pool).

\section{Community}

stability and

resilience

Functional

redundancy $(\mathrm{FR})$
Species sharing similar functional traits and in turn similar roles in ecosystem functioning; high FR suggests strong community stability: the risk of losing ecosystem functions by losing species from a unique functional group is low.

The diversity of responses to environmental changes and disturbances among species that contribute to similar ecosystem

Response diversity (RD) functions (therefore within a single functional group); high RD indicates that a community may be resilient to several types of disturbances because of existing distinct traits allowing species to respond differently to environmental change.
Yes Yes

al., 2007

Ricotta et

al., 2016

Elmquist et

al., 2003

No Yes

Laliberté et

al., 2010 


\section{Figures legends}

Figure 1 Plant community $\alpha$-diversity in recent woodlands and ancient forests. (a) Richness (for the three diversity facets) and divergence (for the functional and phylogenetic facets) of the communities of each forest category. (b) Functional and phylogenetic SES (Standardized Effect Size) values of richness and divergence-dispersion metrics of communities. Negative SES values indicate clustering, while positive values indicate overdispersion. Null values (i.e. showing no difference with null distribution) indicate random patterns of assembly. Graphs show boxplots and means \pm standard errors. See methods for further details on the calculation of these indices and associated statistical tests.

Figure 2 Composite view of conservation importance (a) and resilience (b) of plant communities of recent woodlands and ancient forests combining functional and phylogenetic metrics. Graphs show both boxplots and means \pm standard errors. See methods for further details on the calculation of these indices and associated statistical tests.

Figure 3 Ordinations of taxonomic, functional, and phylogenetic pairwise dissimilarities (Jaccard's index) of assemblages by non-metric multidimensional scaling (NMDS) for the 36 studied assemblages. Overlap between plant communities of recent woodlands and ancient forests is illustrated with one-dimension density (at the top of each graph for the horizontal axis of the NMDS, and on the right of each graph for its vertical axis) as well as two-dimensional kernel density (outer hull for 75\%). Boxplots represent $\beta$-dispersion, a measure of within $\beta$-diversity that assesses the distance of the communities to the group centroid. 
(a)

Functional
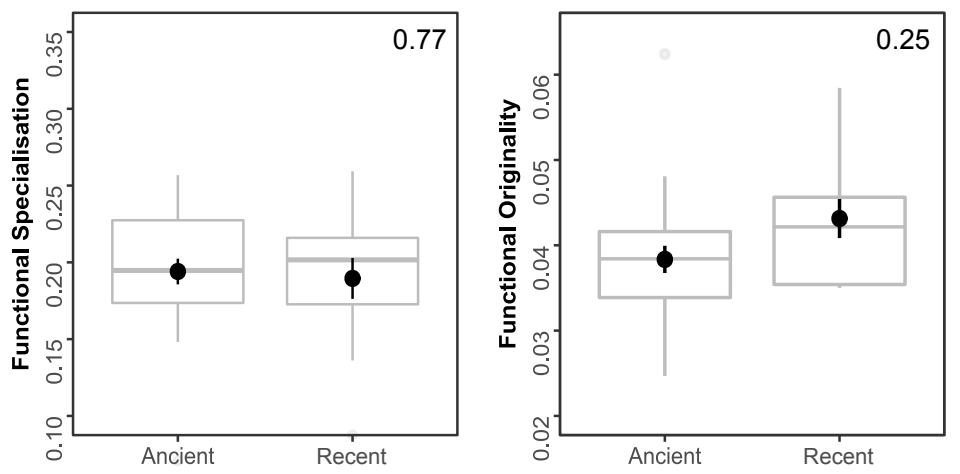

(b)
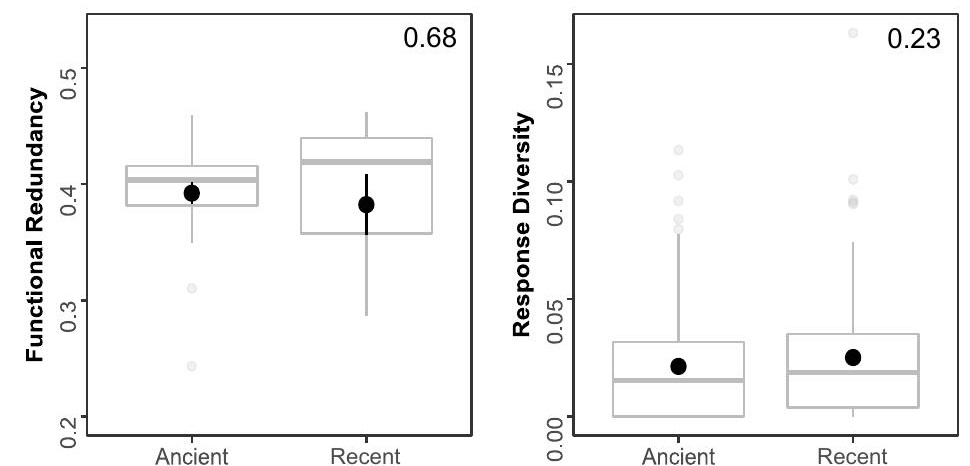

Phylogenetic

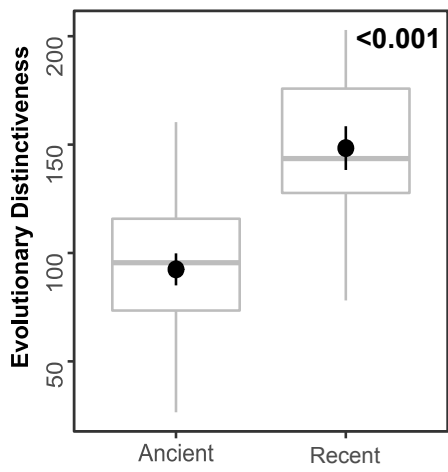


